\title{
Gender Disparities in Open Globe Injuries: Ten- Year Review of an Urban Population
}

\author{
Parisa Emami-Naeini ${ }^{1}$, Alain M. Bauza ${ }^{1}$, Paul D. Langer ${ }^{1}$, \\ Marco A. Zarbin ${ }^{1}$ and Neelakshi Bhagat ${ }^{1^{*}}$ \\ ${ }^{1}$ The Institute of Ophthalmology and Visual Science, New Jersey Medical School, Doctors \\ Office Center, Suite 6100, Newark, NJ 07101-1709.
}

\begin{abstract}
Authors' contributions
This work was carried out in collaboration between all authors. Author PEN wrote the first draft of the manuscript and performed data analysis; author AMB performed data collection; authors PDL and MAZ revised the manuscript and reviewed the literature, author NB performed part of data collection, designed the study, analysed the data, revised and wrote

the final manuscript and reviewed the literature. All authors read and approved the final
\end{abstract} manuscript.

Research Article

Received $18^{\text {th }}$ February 2013

Accepted $5^{\text {th }}$ April 2013

Published 23 ${ }^{\text {rd }}$ April 2013

\section{ABSTRACT}

Aims: To characterize gender differences in the ophthalmic findings and clinical outcomes of patients with open globe (OG) injuries.

Study Design: Retrospective case series.

Place and Duration of Study: Department of Ophthalmology, University Hospital, New Jersey Medical School between January 2001 and June 2010.

Methodology: The medical records of all patients presenting with OG injuries to University Hospital, Newark, NJ from January 1, 2001 through June 30, 2010 were reviewed. Demographics, characteristics of the trauma, ophthalmic findings, and outcomes were compared in male and female patients.

Results: A total 603 eyes (602 patients) with OG injuries were identified. Most of the patients (76.4\%) were male. The mean patient age was 39.14 years which was significantly lower in males (35.66 years vs. 50.43 years in females; $p<0.001$ ). The vast majority of injuries were penetrating and/or work-related in men, whereas fall-related ruptures comprised the most common pattern of injury in women. Zone I was the most commonly injured zone in both genders, and Zone III wounds were more commonly seen 
in males $(p=0.03)$. Although females were more likely to present with a worse visual acuity (VA, $\mathrm{p}=0.005)$, the final VA was not significantly different between males and females $(p=0.06)$, and a statistically significant improvement in vision occurred in both genders $(p<0.001$ in both). Fifteen percent of patients had an unfavorable anatomic outcome and underwent either primary or secondary enucleation; the rate was not different among males and females (17\% in both).

Conclusion: Male and female victims of OG injuries follow different trends in terms of demographics, etiology, and type of injury. This highlights the importance of applying different prevention strategies in the genders.

Keywords: Trauma; open globe injury; gender differences; epidemiology; enucleation.

\section{INTRODUCTION}

Ocular injuries are among the most common preventable causes of vision loss in the United States and worldwide [1-6]. Globally, there are more than 2 million eye injuries annually, constituting a major cause of vision loss and morbidity [7-10]. Ocular trauma is the second most common etiology of vision loss in the US, and open globe (OG) injuries, defined as full thickness eye-ball wounds [5,11], are the most vision threatening [1,12-15].

In general, ocular injuries affect men more often than women, which is similar to the demographics of other types of trauma [2,9,16-21]. Likewise, gender disparities are appreciable in OG injuries: ocular injuries occur in younger males and bear a worse visual prognosis in females [17].

Several studies have been conducted to characterize the gender differences in trauma, yet there is scarcity of papers on the gender differences in OG injuries [17]. In the present study, we characterize the OG wounds presenting to a level I ocular trauma center and describe the gender disparities in a large population of patients with OG injuries.

\section{MATERIALS AND METHODS}

In a retrospective study, we reviewed charts of 602 consecutive patients (603 eyes) presenting with OG injuries to University Hospital, Newark, NJ from January 1, 2001 through June 30, 2010. The study protocol was approved by the University of Medicine and Dentistry of New Jersey (UMDNJ) Institutional Review Board.

Open globe injury was defined according to the Birmingham Eye Trauma Terminology (BETT) as a full thickness wound of the cornea and/or sclera [5]. We reviewed all the charts and created a computerized database for further analysis. The OG injuries database included information on: demographics (age, gender, and ethnicity); mechanism and type of injury; zone of injury; presence of an intraocular foreign body (IOFB); presence of an afferent papillary defect (APD); posterior segment injuries including vitreous hemorrhage (VH), hemorrhagic choroidal detachment $(\mathrm{HC})$, and retinal detachment $(\mathrm{RD})$; presenting visual acuity (VA); surgical interventions; and final visual and anatomic outcomes. For analysis of VA data, the Snellen chart VA was converted to logMAR (logarithm of the minimal angle of resolution) [22], and patients who underwent enucleation were considered no light perception (NLP) when final VA calculations were made. 
Type and zone of injury were defined according to the classification put forth by the BETT study [5]. Three types of OG injuries are defined: penetrating (only an entrance site present), perforating (entrance and exit wounds are present), and rupture (full thickness wound induced by a blunt object). Full thickness wounds can involve 3 different sites [23]: zone I (wound limited to the cornea and the limbus), zone II (wound extends only into the anterior $5 \mathrm{~mm}$ sclera) and zone III (wound extends into a region more than $5 \mathrm{~mm}$ posterior to the limbus).

The final outcome measures analyzed included the anatomic (need for enucleation) and visual outcomes (poor final vision and/or vision of NLP). Poor final visual outcome was defined as final VA of less than 20/400.

Statistical analysis was performed using either 2-tailed student's t-test, to compare means, or $x^{2}$ test of independence for categorical data. SPSS software (version 18, SPSS Inc.) was used for the analysis with probability levels of lower than 0.05 considered statistically significant.

\section{RESULTS AND DISCUSSION}

A total of 603 eyes (602 patients) presented with OG injuries to University Hospital from January 1,2001 to June 30,2010 . Four hundred and sixty patients $(76.4 \%)$ were male, and $142(23.6 \%)$ were female. The mean patient age was 39.14 years, which was significantly lower in males (35.66 years vs. 50.43 years in females; $p<0.001$ ). Nearly half of the male patients $(41.3 \%)$ fell in the range of $19-34$ years age group, whereas $38 \%$ of females were 65 years or older (Table 1). Sixteen percent of the patients had at least one surgery on the injured eye. Compared to males, female patients were more likely to have had previous ophthalmic procedures ( $31.7 \%$ in females vs. $11.2 \%$ in males; $p<0.001)$.

Table 1. Age (years) and gender distribution of patients with open globe injuries

\begin{tabular}{llll}
\hline Age range & Men & Women & Total \\
\hline $0-18$ & $57(12.4)$ & $22(15.5)$ & 79 \\
$19-34$ & $190(41.3)$ & $26(18.3)$ & 216 \\
$35-64$ & $176(38.3)$ & $40(28.2)$ & 216 \\
$\leq 65$ & $37(8)$ & $54(38)$ & 91 \\
Total & 460 & 142 & 602 \\
\hline
\end{tabular}

The underlying etiology of $O G$ injury was different in male and female patients (Table 2). While work-related wounds were the most common wounds in males $(40.6 \%)$, trauma due to fall comprised the most frequent etiology in women (34.1\%). Other causes of trauma included: assault (injuries with glass bottles, fists, firearms, blunt objects, etc.), seen in 146 patients with $82 \%$ of the victims being male; motor vehicle accidents (29 patients, $69 \%$ were female); and other mechanisms of OG injury (summarized in Table 2).

Anterior globe injuries, involving only zone I, were the most common wounds in both genders and were observed in $43.6 \%$ of males and $50.4 \%$ of females. On the other hand, zone III injuries were significantly more common among male patients ( $\mathrm{OR}=1.5, p=0.03$ ). Comparing different types of globe injury, men were more likely to suffer from penetrating injury $(60.8 \%)$ whereas rupture was the most frequent type of OG injuries in women $(67 \%$, $p<0.001)$. Perforating injuries were the least common in both genders $(2.4 \%$ of males and 
$1.4 \%$ of females). Likewise, IOFBs were more commonly present in male patients $(11.7 \%$ vs.1.4\%; $p<0.001)$. The rate of endophthalmitis was also higher in males, although the difference was not statistically significant $(2.4 \%$ in males vs. $1.4 \%$ in females; $p=0.4)$.

Posterior segment complications, including $\mathrm{VH}, \mathrm{RD}$ and $\mathrm{HC}$, were diagnosed in 310 eyes. Fifty eight percent of males ( 237 eyes) and $55 \%$ of females (73 eyes) were noted to have at least one of the aforementioned posterior segment injuries, and there was no statistically significant difference between genders $(p=0.9)$. Other characteristics and clinical findings of the study population are summarized in Table 2 .

\section{Table 2. Demographics and baseline clinical characteristics of the male and female} patients with open globe injuries

\begin{tabular}{|c|c|c|c|}
\hline \multirow{3}{*}{$\begin{array}{l}\text { Ethnicity } \\
(456)^{*}\end{array}$} & \multirow{5}{*}{$\begin{array}{l}\text { African-American } \\
\text { Hispanic } \\
\text { Caucasian } \\
\text { Other }\end{array}$} & \multirow{2}{*}{$\begin{array}{l}\text { Men (\%) } \\
109(31)\end{array}$} & \multirow{2}{*}{$\begin{array}{l}\text { Women (\%) } \\
47(44.8)\end{array}$} \\
\hline & & & \\
\hline & & $111(31.6)$ & $12(11.4)$ \\
\hline & & $77(22)$ & $38(36.2)$ \\
\hline \multirow{6}{*}{$\begin{array}{l}\text { Etiology } \\
(582)\end{array}$} & & $54(15.4)$ & $8(7.6)$ \\
\hline & Assault & $120(27.5)$ & $26(17.7)$ \\
\hline & Fall & $35(8)$ & $50(34.1)$ \\
\hline & MVA & $9(2.1)$ & $20(13.6)$ \\
\hline & Work-related & $177(40.6)$ & $6(4)$ \\
\hline & Other & $95(21.8)$ & $45(30.6)$ \\
\hline Type & Penetrating & $276(60.8)$ & $44(31.6)$ \\
\hline \multirow{2}{*}{$(593)^{*}$} & Perforating & $11(2.4)$ & $2(1.4)$ \\
\hline & Rupture & $167(36.8)$ & $93(67)$ \\
\hline \multirow{3}{*}{$\begin{array}{l}\text { Zone } \\
(586)^{*}\end{array}$} & Zone I & $196(43.6)$ & $69(50.4)$ \\
\hline & Zone II & $103(23)$ & $34(24.8)$ \\
\hline & Zone III & $150(33.4)$ & $34(24.8)$ \\
\hline \multicolumn{2}{|c|}{ Enucleation (602) } & $71(15.4)$ & $22(15.5)$ \\
\hline \multicolumn{2}{|c|}{$\mathrm{VH}^{*}(574)^{*}$} & $186(42.1)$ & 59 (43.7) \\
\hline \multicolumn{2}{|c|}{$H C^{*}(575)^{*}$} & $116(23.4)$ & $41(30.3)$ \\
\hline \multirow{2}{*}{\multicolumn{2}{|c|}{$\begin{array}{l}\text { APD }(344)^{*} \\
\end{array}$}} & $90(32.2)$ & $28(43)$ \\
\hline & & $224(49.9)$ & $77(56.2)$ \\
\hline \multicolumn{2}{|l|}{$\mathrm{RD}(574)^{*}$} & $162(36.8)$ & $36(26.8)$ \\
\hline \multicolumn{2}{|c|}{ IOFB $(603)^{x}$} & $54(11.7)$ & $2(1.4)$ \\
\hline \multicolumn{2}{|c|}{ Endophthalmitis (593) } & $11(2.4)$ & $2(1.4)$ \\
\hline
\end{tabular}

${ }^{*}$ As data were not available in all of the patients, numbers in parentheses denote number of patients for whom data was available.

MVA: motor vehicle accident; VA: visual acuity; VH: vitreous hemorrhage; $H C$ : hemorrhagic choroidal detachment; APD: afferent papillary defect; RD: retinal detachment; IOFB: intraocular foreign body.

Data on initial VA were present in 528 eyes (Table 3 ). The mean initial logMAR VA ( $\pm S D$ ) of females was $2.17( \pm 0.71)$, which was significantly worse than of males (1.92 \pm 0.87 ; $\mathrm{p}=0.005)$. The majority of the patients $(411,77.8 \%)$ presented with VA of less than $20 / 400$, and only 31 patients $(5.8 \%)$ presented with vision of $20 / 40$ or better. Compared to males, female patients were more likely to present with initial VA of $<20 / 400(86.9 \%$ of women vs. $75.1 \%$ of men; $p=0.005$, OR=2.23). A total of 114 patients $(21.5 \%)$ presented with vision of NLP, which was not statistically different between genders $(p=0.48)$. 
Table 3. Baseline and final vision in patients with open globe injuries

\begin{tabular}{llll}
\hline & Visual Acuity & Presenting VA $^{*} \mathbf{( 5 2 8 )}$ & Final VA $^{*}(\mathbf{5 6 0})$ \\
\hline Men & $\leq 20 / 40$ & $26(6.4)$ & $92(21.4)$ \\
\multirow{2}{*}{ no. eyes(\%)\} } & $20 / 400-20 / 40$ & $75(18.5)$ & $90(21)$ \\
& HM/LP & $220(54.2)$ & $132(30.7)$ \\
Women & NLP & $85(20.9)$ & $46(10.7)$ \\
& enucleation & & $71(16.9)$ \\
\multirow{2}{*}{ no. eyes(\%)\} } & $\leq 20 / 40$ & $5(4)$ & $12(9.2)$ \\
& 20/400-20/40 & $11(9.1)$ & $33(25.4)$ \\
& HM/LP & $77(63.1)$ & $45(34.6)$ \\
& NLP & $29(23.8)$ & $19(14.6)$ \\
& Enucleation & & $22(16.9)$ \\
\hline
\end{tabular}

${ }^{*}$ As data were not available for all of the patients, numbers in parentheses denote number of patients for whom data was available.

VA: visual acuity; HM: hand motion; LP: light perception; NLP: no light perception.

Final VA was available in 560 patients. A statistically significant improvement in VA was appreciated in both men and women ( $p<0.001$ in both). However, the mean logMAR final VA was worse among women, but the difference was not statistically significant (1.6 \pm 1.09 in men vs. $1.8 \pm 1.01$ in women; $p=0.06$ ).

Unfavorable anatomic outcome, defined as the need for enucleation, was noted in 93 eyes (15.4\%). This procedure was performed mainly due to blind painful eye, phthisis bulbi, or endophthalmitis. All 93 eyes enucleated had VA of NLP and were for severe pain. Two-thirds (62 of 93 eyes) sustained a rupture type of injury. The predominant anatomic site of the fullthickness wound was zone 3 in 55 eyes (59.1\%). Twenty-one (all NLP) of 93 eyes were deemed unsalvageable at presentation and underwent primary enucleation. The remaining 72 eyes (VA at presentation: 17 LP; 55 NLP) underwent primary globe repair. All except 2 had disorganised globe on $\mathrm{B}$-scan with $\mathrm{RD}, \mathrm{VH}$ and hemorrhagic choroidals. Two eyes were diagnosed with endophthalmitis. Only 15 of 72 eyes were LP vision after globe repair; 7 of these underwent PPV and drainage of hemorrhagic choroidals but in follow-up visits were found to be NLP. All 72 eyes became NLP and were enucleated at a mean duration of 43 days after primary globe repair either to decrease the risk of sympathetic ophthalmia or for severe pain. The rate of enucleation, either primary or secondary, was not significantly different between male and female patients (17\% in both groups, Table 3$)$.

Open globe injuries are one of the most common, yet preventable, causes of vision loss and monocular blindness worldwide [17,24]. While these wounds affect both genders, the epidemiology and patterns of injury seem to be gender specific. The majority of victims are male, accounting for $73-81 \%$ of the patients in various studies $[2,8,17,21,25]$, consistent with the results in this series $(76.5 \%$ of patients were male).

Age distribution of the patients was also different between genders. Female patients tended to be of older age group (38\% older than 64 years) compared to men ( $41 \%$ between ages 19-34 years). This result may be attributed to the underlying mechanism of injury. In the present series, OG injuries in women were due primarily to falls vs. OG injuries in men, which were due primarily to work-related events. Fall-related injuries more commonly affecting the elderly [8]. In contrast, work-related OG injuries occur more often among young, otherwise healthy men [18]. 
Penetrating trauma comprised the most common type of OG injuries in males while women were more likely to suffer from a ruptured globe, which is consistent with previous studies $[17,24]$. The high prevalence of rupture injuries in female patients could be due to the higher rate of fall-related OG wounds in this population. Moreover, their older age and possible previous ocular surgeries render them susceptible to globe rupture following fall-related blunt trauma.

Different ocular zones are involved in male and female OG injuries. Koo et al. [17] reported that male patients were more prone to zone I involvement while females were more commonly affected by zone II injuries [17]. However, this was not the case in our series, where zone I was the most common location of injury in both genders. Furthermore, zone III injuries were significantly more common among males $(p=0.03)$.

Female patients presented with significantly worse vision. This finding might be explained by other characteristics of $O G$ injuries in females: these patients were of older age and might have been suffering from vision loss even prior to the injury. Moreover, fall-related globe ruptures generally result in a poor visual outcome [8] . On the other hand, male victims were younger, with work-related injuries being the most common etiology of OG injuries which generally exhibit a better final VA compared to non work-related OG wounds [18].

It has previously been suggested that female patients usually attain a worse final VA [17]. This trend, although not statistically significant $(p-0.06)$, was also seen in the present series. Regardless of gender, all patients showed a statistically significant improvement in the final VA, which was more remarkable in females. The anatomic outcome of the two groups of patients was not significantly different in our series.

\section{CONCLUSION}

The present study provides epidemiologic data on OG injuries and disparities between male and female patients. We clearly demonstrated that there exist several differences between male and female victims of OG wounds in terms of underlying etiology, severity of involvement, and final prognosis. While young men are at higher risk of work-place ocular injuries, elderly females are more likely to be affected by fall-related wounds. This result highlights the necessity of applying distinct measures for preventing ocular injuries in male and female patients.

\section{CONSENT AND ETHICAL APPROVAL}

This retrospective chart review study was performed within the guidelines of research at the University of Medicine and Dentistry of New Jersey (UMDNJ). An Institutional Review Board approval at UMDNJ was taken before the study was commenced.

\section{ACKNOWLEDGEMENTS}

The study was sponsored by Research to Prevent Blindness and Lions Eye Institute.

\section{COMPETING INTERESTS}

Authors have declared that no competing interests exist. 


\section{REFERENCES}

1. May D, Kuhn F, Morris R, et al. The epidemiology of serious eye injuries from the United States Eye Injury Registry. Graefes Arch Clin Exp Ophthalmol. 2003;238(2):153-157.

2. Kim J, Yang S, Kim D, Kim J, Yoon Y. Fourteen-year review of open globe injuries in an urban Korean population. J Trauma. 2007;62(3):746-749.

3. Matthews G, Das A, Brown S. Visual outcome and ocular survival in patients with retinal detachments secondary to open- or closed-globe injuries. Ophthalmic Surg Lasers. 1998;29(1):48-54.

4. Rofail M, Lee G, O'Rourke P. Prognostic indicators for open globe injury. Clin Experiment Ophthalmol. 2006;34(8):783-786.

5. Kuhn F, Morris R, Witherspoon C. Birmingham Eye Trauma Terminology (BETT): terminology and classification of mechanical eye injuries. Ophthalmol Clin North Am. 2002;15(2):139-143.

6. Kuhn F, Morris R, Mester V, Witherspoon C, Mann L, Maisiak R. Epidemiology and socioeconomics. Ophthalmol Clin North Am. 2002;15(2):145-151.

7. Wong T, Tielsch J. A population-based study on the incidence of severe ocular trauma in Singapore. Am J Ophthalmol. 1999;128:345-351.

8. Kuhn F, Morris R, Witherspoon C, Mann L. Epidemiology of blinding trauma in the United States Eye Injury Registry. Ophthalmic Epidemiol. 2006;13(3):209-216.

9. $\quad$ Fong L. Eye injuries in Victoria, Australia. Med J Austral. 1995;162:64-68.

10. Byhr E. Perforating eye injuries in a western part of Sweden. Acta Ophthalmol. 1994;72:91-97.

11. Kuhn F, Morris R, Witherspoon C, Heimann K, Jeffers J, Treister G. A standardized classification of ocular trauma. Graefes Arch Clin Exp Ophthalmol. 1996;234(6):399403.

12. Parver L. Eye trauma. The neglected disorder. Arch Ophthalmol. 1986;104(10):14521453.

13. Esmaeli B, Elner S, Schork M, Elner V. Visual outcome and ocular survival after penetrating trauma. A clinicopathologic study. Ophthalmology. 1995;102(3):393-400.

14. Thach A, Johnson A, Carroll R, et al. Severe eye injuries in the war in Iraq, 2003-2005. Ophthalmology. 2008;115(2):377-382.

15. Casson R, Walker J, Newland H. Four-year review of open eye injuries at the Royal Adelaide Hospital. Clin Experiment Ophthalmol. 2002;30(1):15-18.

16. Breslau N. Gender Differences in trauma and posttraumatic stress disorder. J Gend Specif Med. 2002;5(1):34-40.

17. Koo L, Kapadia M, Singh R, Sheridan R, Hatton M. Gender differences in etiology and outcome of open globe injuries. J Trauma. 2005;59(1):175-178.

18. Kanoff J, Turalba A, Andreoli M, Andreoli C. Characteristics and outcomes of workrelated open globe injuries. Am J Ophthalmol. 2010;150(2):265-269.

19. Hyun Lee S, Ahn J. Emergent risk factors associated with eyeball loss and ambulatory vision loss after globe injuries. J Trauma. 2010;69(1):195-198.

20. Groessl S, Nanda S, Mieler W. Assault-related penetrating ocular injury. Am J Ophthalmol. 1993;116(1):26-33.

21. Lesniak S, Bauza A, Son J, Zarbin MA, Langer P, Guo S, Wagner R, Bhagat N. Twelve-Year Review of Pediatric Traumatic Open Globe Injuries in an Urban U.S. Population. J Pediatr Ophthalmol Strabismus. 2012;49(2):73-9.

22. Arroyo J, Postel E, Stone T, McCuen B, Egan K. A matched study of primary scleral buckle placement during repair of posterior segment open globe injuries. $\mathrm{Br} \mathrm{J}$ Ophthalmol. 2003;87(1):75-78. 
23. Pieramici $D$, Sternberg $P$, Aaberg $T$, et al. A system for classifying mechanical injuries of the eye (globe). The Ocular Trauma Classification Group. Am J Ophthalmol. 1997;23(6):820-831 .

24. Andreoli M, Andreoli C. Geriatric traumatic open globe injuries. Ophthalmology. 2011;118(1):156-159.

25. Sterling D, O'Connor J, Bonadies J. Geriatric falls: injury severity is high and disproportionate to mechanism. J Trauma. 2001;50(1):116-119.

(C) 2013 Emami-Naeini et al.; This is an Open Access article distributed under the terms of the Creative Commons Attribution License (http://creativecommons.org/licenses/by/3.0), which permits unrestricted use, distribution, and reproduction in any medium, provided the original work is properly cited.

Peer-review history:

The peer review history for this paper can be accessed here: http://www.sciencedomain.org/review-history.php?iid=205\&id=12\&aid=1273 